\title{
Phase Equilibrium Study for the Separation of Solid Components Using Supercritical Carbon Dioxide
}

\author{
Abdul Mun'em Abbas Karim¹, Dhia M. Kassim² and Mohammed Salah Hameed ${ }^{3} *$ \\ ${ }^{1}$ College of Engineering, University of Diyala, Baquba, Diyala, Iraq \\ ${ }^{2}$ Chemistry Research and Petrochemicals Industry, Ministry of Science and Technology, Iraq \\ ${ }^{3}$ Chemical Engineering, Higher Colleges of Technology, P.O. Box 25035, Abu Dhabi, United Arab Emirates
}

\begin{abstract}
The equilibrium mole fraction solubility of low volatile solid components (naphthalene and phenanthrene) in supercritical pure carbon dioxide was studied at temperature range (308.15-333.15 K) and pressures up to 200 bars. In the present study a measure of the effect of temperature and pressure were considered in the extraction process using supercritical carbon dioxide. The experiments were carried out using a designed apparatus similar to that used by King et al., [1]. In this apparatus, the extracted gas (carbon dioxide) was re-circulated continuously over the component to be extracted via a sample bomb till equilibrium is reached. The sample bomb is then isolated and its contents were analyzed.
\end{abstract}

The results of analysis showed that the solubility of naphthalene and phenanthrene expressed in mole fraction depend strongly upon the pressure (density) of the supercritical carbon above the critical density.

The obtained laboratory data are correlated with three cubic equations of state, Redlich-Kwong (RK), Soave-RedlichKwong (SRK), and Peng-Robinson (PR). Comparison of experimental phase equilibrium data with the results predicted by the equations of state shows good representation.

Keywords: High pressure gas-solid equilibrium, binary systems, carbon dioxide, naphthalene, phenanthrene, cubic equations of state.

\section{INTRODUCTION}

Extraction with supercritical solvent is an alternative separation process when other methods such as distillation, absorption or conventional liquid-liquid extraction are impractical or impossible. In particular, thermal processes cannot be applied in presence of thermo-labile compounds, which can generate degradation products. Further-more extraction with conventional solvent is not suitable in the field of pharmaceutical and food industries where the concentration of residual solvent and impurities in the final product must be restrictively low. In this contest supercritical fluid processes are attractive since this alternative method requires low operational temperature (around 313K) and complete solvent separation can be achieved through a simple expansion of the final product [2].

Carbon dioxide is the most commonly used as SCF, due primarily to its low critical parameters $\left(\mathrm{T}_{\mathrm{c}}=304.25 \mathrm{~K}, \mathrm{P}_{\mathrm{c}}=\right.$ 73.8 bars), low cost and non-toxicity. However, several other SCFs have been used in both commercial and development processes. Other features make carbon dioxide $\mathrm{CO}_{2}$ the ideal solvent for supercritical fluid extraction (SFE) that it is not toxic and not inflammable, it can be obtained in large quantities with high purity and at low cost, it is easy to separate (gaseous at atmospheric pressure), and it does not damage the solutes or the matrix of the product [3].

*Address correspondence to this author at the Chemical Engineering, Higher Colleges of Technology, P.O. Box 25035, Abu Dhabi, United Arab Emirates; Tel: +97124048264; Fax: +97124048390; E-mail: mhameed@hct.ac.ae
The solvent strength of the SCF is a function of its density, and the density is a function of temperature and pressure. Hence with controlling temperature and pressure, solvent strength of the SCF can be controlled [4]. The main advantage of SCF over liquid solvents arises from this concept.

As a separation technology, SFE has considerable potential for commercial utilization. Although equipment investment costs are high, this is not the factor limiting widespread commercialization. The limitation is the lack of knowledge of the phase behavior of multicomponent mixtures near their critical points. This lack of knowledge prevents the optimal design of supercritical solvent systems, which in turn keeps the cost high [5].

Among all the wide variety of interesting studies that can emerge from this technology, all of studies focused on three main concerns to obtain a better insight into SCF:

1. The computational study of high-pressure and multiphase equilibrium and the importance of mathematical validation of the number of phases and composition.

2. The experimental and modeling of solubilities of solutes in SCF.

3. The design and optimization of supercritical fluid extraction (SFE) processes [6].

The present work will take the care of point (1) and (2) only, and will measure solubilites of naphthalene and phenanthrene as solid components in supercritical $\mathrm{CO}_{2}$ solvent at constant temperature and different high pressures and try to correlate the experimental solubilities of solid solute with cubic equations of state using van der Waals mixing rules. 


\section{LITERATURE REVIEW}

The experimental results of naphthalene solubility in SCF's slowed until the late 1940s. But in 1948, a study of the solubility and phase behavior of naphthalene dissolved in supercritical ethylene was reported by Diepen and Scheffer [7].

Francis [8] presented an extensive, quantitative study on the solvent properties of liquid carbon dioxide with hundreds of compounds. He was primarily interested in the phase behavior of ternary systems containing liquid carbon dioxide. He collected data for 464 ternary phase diagrams and determined the solubilities of 261 compounds in near-critical liquid carbon dioxide. Although Francis studied solubility behavior (at conditions approximately $298.15 \mathrm{~K}$ and $65.5 \mathrm{bar}$ ), his results are very general.

McHugh \& Paulaitis [9] measured the solid solubility of naphthalene and biphenyl in supercritical carbon dioxide at various isotherms above $304 \mathrm{~K}$-the critical temperature of carbon dioxide- and over a range of pressures from 81.1 to 506.7 bars.

Kurink et al. [10] obtained solubility data for five different solids (including naphthalene and phenanthrene) in both supercritical carbon dioxide and supercritical ethylene by using one-pass flow system at the temperature range (308$338 \mathrm{~K})$ and the pressure range $(80-280$ bar). The data obtained correlated by using thermodynamic relationships and an equation of state.

Johnston et al. [11] presented new data for the solubility of several nonpolar hydrocarbon solids (included naphthalene and phenanthrene) in supercritical ethylene, ethane and carbon dioxide by using the same technique for Johnston and Eckert [12]. The data presented with other data reported previously have been correlated by perturbed hard-sphere equations of state that do not require the use of critical properties.

The solubility data for $\alpha$-pinene, cis-verbenol and naphthalene in carbon dioxide have been measured at the temperatures from $313.15 \mathrm{~K}$ to $328.15 \mathrm{~K}$ and pressures from 50 bar to 120 bar by using a dynamic flow apparatus and they have been correlated using a compressed gas model with the Peng-Robinson equation of state (PR-EOS) and an empirical equations based on the dependence of the concentration of solute on the density of pure solvent by Richter and Sovova' [13].

Sauceau et al. [14] measured solubilities of naphthalene in supercritical $\mathrm{CO}_{2}$ in the pressure range 80-300 bar along the isotherm $308.15 \mathrm{~K}$, then the solubility data are correlated using the Chrastil model.

Hartono et al. [15] used six different cubic equations of state to predict the solubility of solids and they shown that the Mohsen-Nia-Moddaress-Mansoori (MMM) equation is more accurate than five of the other equations.

Unlu [16] and Baskaya [17] measured the solubility of naphthalene in supercritical $\mathrm{CO}_{2}$ at 308 and $318 \mathrm{~K}$ as a calibration of the phase equilibrium analyzer system and compared their results with the literature.

Karim and Abdul Khader [18] studied the phase equiliberia modeling for separation of solid mixtures by supercritical $\mathrm{CO}_{2}$ on Excel program using PR-EOS.
Ajchariyapagorn et al. [19] presented a method to estimate the solubility of solid solutes in supercritical fluids when only the molecule structure is known. They used group contribution methods to estimate pure component properties, equations of state then used to estimate the PVT behavior of the solvent and the fugacity coefficient of solute in the solute-solvent mixture.

The solubility of triclosan, an anti-acne agent measured in supercritical carbon dioxide with a variable volume view cell at $313.15,323.15$, and $333.15 \mathrm{~K}$ and at pressures between 100 and 400 bars by Shin and Kim [20]. Then the data of triclosan solubility in supercritical carbon dioxide correlated using the quasi-chemical nonrandom lattice fluid equation of state.

Karim [21] studied the thermodynamic modeling of solubility of C. I. disperse orange 30 (O30) dye as a solid component in supercritical $\mathrm{CO}_{2}$ using Peng-Robenson equation of state (PR-EOS). The sensitivity of critical properties in the calculations was also studied. He proved that the choice of the technique to calculate thermodynamic properties is very important for obtaining good results in the phase equilibrium calculations.

Karim and Mutlag [22] modeled the experimental data obtained from literatures for the separation of phenanthrene by pure supercritical $\mathrm{CO}_{2}$ and supercritical $\mathrm{CO}_{2}$ entrained with n-pentane as a liquid solvent by using two techniques, Peng-Robinson equation of state (PR- EOS) and Artificial Neural Networks (ANN).

\section{THERMODYNAMIC MODELING}

The calculations of solid-fluid equilibrium at high pressure are important in the modeling and design of processes that use SCFs to selectively extract solid solutes [23].

The phase behavior of solutes in SCF is an important aspect, which is often overlooked in the solubility determinations. In the presence of the solute, the vapor pressure curve for pure $\mathrm{CO}_{2}$ is shifted ending in a critical end point. Also, solid solutes when in contact with supercritical $\mathrm{CO}_{2}$ can exhibit complex phase behavior such as depression in melting point resulting in multiple phases. This depression in melting point can considerably influence the determination of solid solubility. In addition, density inversion may occur and lead to erroneous solubility data. This emphasizes the need for checking the phase equilibrium when the solid solubility data is measured $[24,25]$.

The knowledge of phase behavior of solutes of interest under the SCF conditions is also essential for the development of any SCF process. Despite its importance there is very limited data on the phase behavior of solid solutes in supercritical $\mathrm{CO}_{2}$, which is particularly true for multicomponent systems. The reasons for lack of phase behavior data can be attributed to the fact that specialized equipment is required and the experiments are generally tedious and time consuming [25].

Many models for supercritical-phase equilibrium treat the SCF phase as a dense gas and use an equation of state to calculate the fugacity of the solute in the fluid phase. The results of these models are frequently very sensitive to the interaction energies and size factors, necessitating the need 
to develop improved mixing rules to estimate the mixture size and energy parameters needed in the equation of state.

Cubic equations of state are exceedingly simple, have been remarkably successful in modeling SCF-phase behavior, and are probably the most widely used in analyzing experimental data.

Cubic equations of state can take different forms from ideal gas law to more complicated forms. More complicated equations usually give more accurate results but only at the expense of being more computationally complex. For this reason it is often preferred to work with simpler EOS, which still gives satisfactory results.

In the present work, the RK, SRK, and PR-EOS were chosen to model the high-pressure phase behavior that are developed first for pure component, and then extended to mixtures through the use of mixing rules for combining the pure component parameters. For the mixture, the conventional van der Waals mixing rules were used:

$a_{m}=\sum_{i}^{n} \sum_{j}^{n} y_{i} y_{j} a_{i j}$

$b_{m}=\sum_{i}^{n} y_{i} b_{i}$

where,

$a_{i j}=\left(a_{i} a_{j}\right)^{0.5}\left(1-k_{i j}\right)$

where $a_{i}$ and $b_{i}$ are calculated using the critical pressure $P_{c}$, critical temperature $T_{c}$ and acentric factor $\omega$ for each component. The physical properties of the pure components used in the present work are summarized in Table (1). In equation (3), $\boldsymbol{k}_{i j}$ is the binary interaction parameter, which has a nonzero value.

\section{Solid - Fluid Phase Equilibrium}

Solid solubility in SCF refers to its composition in the vapor phase. The solids of interest in most SCF processes have low volatility and differ greatly from the SCF in chemical nature. In these systems the phase behavior is complex, especially if multiple solutes are present. The limiting case of a binary system consisting of single solid in a SCF offers a basis for understanding the phase behavior in multicomponent systems [25].

The most important application of the equation of state approach lies in computing solubilities of relatively nonvolatile solids in supercritical fluids. To analyze this phenomenon, it will start with the equality of the species fugacities in each phase. However, since the fluid (liquid, gas, or supercritical fluid) is not present in the solid (or it contains a neg- ligible amount), two simplifications arise. First, the equilibrium criterion applies only to the solid solute, which it is denoted by the subscript $i$, and second; the solid phase fugacity of the solute is that of the pure solid. Thus a single equilibrium relation will be presented as:

$$
f_{i}^{S}(T, P)=f_{i}^{S C F}\left(T, P, y_{i}\right)
$$

where the superscript $\mathbf{S}$ and SCF refer to the pure solid and supercritical fluid phases, respectively, then $f_{i}^{S C F}$ can be expressed as:

$f_{i}^{S C F}=\phi_{i}^{S C F} y_{i} P$

where $\left(y_{i}\right)$ is the mole fraction of solid in the gas phase, $\phi_{i}^{S C F}$ is the gas phase fugacity coefficient, $f_{i}^{S}$ is the fugacity of solid and it has pressure units.

For each component (i) in the fluid phase (vapor, liquid phase or supercritical state) [26]:

$\ln \phi_{i}=\frac{1}{R T} \int_{v^{v}}^{\infty}\left[\left(\frac{\partial P}{\partial n_{i}}\right)_{T, v, n_{j}}-\frac{R T}{\underline{V}}\right] d \underline{V}-\ln Z$

where $\underline{\mathrm{V}}$ is the total system volume, $\mathrm{n}_{\mathrm{i}}$ and $\mathrm{n}_{\mathrm{j}}$ are the number of moles of components $\mathrm{i}$ and $\mathrm{j}$ respectively.

When the cubic equation of state (RK, SRK, or PR) is introduced into Eq. (6) using mixing rules, given by Eqs. (1) and (2), the fugacity coefficient is obtained.

Because the solid phase is normally considered a pure solid (i.e. the SCF solvent does not dissolve in the solid), the fugacity $f_{i}^{S}$ is,

$f_{i}^{s}=P_{i}^{s u b}(T) \phi_{i}^{s u b}\left(T, P_{i}^{s u b}\right) \exp \left[\int_{P_{i}^{s u b}}^{P}\left(\frac{v_{i}^{s}}{R T}\right) d P\right]$

where $\mathrm{P}_{\mathrm{i}}^{\text {sub }}(\mathrm{T})$ is the sublimation or vapor pressure of the pure solid at the system temperature, $v_{i}{ }^{s}$ the molar volume of the pure solid and is independent of pressure, $\phi_{i}^{\text {sub }}\left(T, P_{i}{ }^{\text {sub }}\right)$ is the fugacity coefficient at $\mathrm{T}$ and $\mathrm{P}_{\mathrm{i}}^{\text {sub }}$ to be assumed unity, and the exponential term is the Poynting factor correction for the fugacity of the pure solid. Therefore, combining Eqs. (5) and (7) for unity $\phi_{i}^{\text {sub }}\left(\mathrm{T}, \mathrm{P}_{\mathrm{i}}^{\text {sub }}\right)$, the mole fraction solubility of a heavy nonvolatile solid in the SCF solvent phase now becomes,

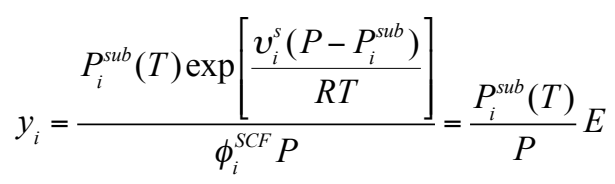

where,

Table 1. The Physical Properties of Components Studied [17]

\begin{tabular}{|c|c|c|c|c|}
\hline Component & $v^{\text {s }}$ (lit./mol) & $\omega$ & $\mathbf{P}_{\mathrm{c}}$ (bar) & $\mathbf{T}_{\mathrm{c}}(\mathbf{K})$ \\
\hline Carbon dioxide & - & 0.2250 & 73.80 & 304.10 \\
\hline Naphthalene & 0.1114 & 0.3030 & 40.50 & 748.40 \\
\hline Phenanthrene & 0.1820 & 0.4396 & 28.97 & 878.78 \\
\hline
\end{tabular}




$$
E=\frac{\exp \left[\frac{v_{i}^{s}\left(P-P_{i}^{s u b}\right)}{R T}\right]}{\phi_{i}^{S C F}}
$$

$E$ is called enhancement factor and generally greater than unity. The most significant quantity in this factor is $\phi_{i}^{S C F}$. Especially at low temperatures, $E$ can exceed $10^{3}$ or more because of $\phi_{i}^{S C F}$.

The partial molar volume of the solid components at all pressures and temperatures is assumed equal to its molar volume at atmospheric pressure and $298 \mathrm{~K}$, and this will be closer to the truth [27].

The vapor pressures of solid components studied calculated by the following equation:

$$
\ln \left(P^{s u b}\right)=\alpha+\frac{\beta}{T}
$$

where $\mathrm{P}^{\text {sub }}$ in $\mathrm{N} / \mathrm{m}^{2}$, $\mathrm{T}$ in $\mathrm{K}$, and $\alpha$ and $\beta$ are constants and shown in Table (2).

Table 2. The Constants of Eq. [10, 28]

\begin{tabular}{|c|c|c|}
\hline Solid Component & $\boldsymbol{\alpha}$ & $\boldsymbol{\beta}$ \\
\hline \hline Naphthalene & 31.5997 & -8711.7396 \\
\hline Phenanthrene & 31.8320 & -10715.3350 \\
\hline
\end{tabular}

\section{EXPERIMENTAL}

The experimental apparatus and procedures used in the present work are similar to those of King et al. [1] and Kassim et al. [29] and it is described in details by Karim [28] and are summarized briefly below.

A schematic flow diagram for the equipment is given in Fig. (1). The apparatus consists essentially of the following parts, 1 . The equilibrium cell, 2 . The vapor sampling bomb, 3 . The circulation pump (driven by compressed air from a compressor) which recirculates the extracting phase through the equilibrium cell and sampling bomb, 4. The sampling unit, consisting of two glass receivers, an expansion vessel and vacuum system, 5. Mercury pump which uses to increase the pressure of the carbon dioxide gas and in pressure vessel, 6. Valves and connecting tubing.

The equilibrium cell was constructed of stainless steel and was supplied by Ruska Co. It has a volumetric capacity of the equilibrium cell was about $1000 \mathrm{~cm}^{3}$ and is designed to operate at pressured up to about $300 \mathrm{bar}$ and temperatures up to $200^{\circ} \mathrm{C}$ and is shown in Fig. (2). The vapor sampling bomb is the high pressure part of the sampling system; it was constructed of stainless steel and supplied by Ruska Co. The vapor sampling bomb has a capacity of $25 \mathrm{~cm}^{3}$ and is designed for a maximum working pressure of $800 \mathrm{bar}$ and temperatures up to $200^{\circ} \mathrm{C}$. The equilibrium cell, sampling bomb, circulation pump (produced by Haskel Eng. Supply Co. Model MCP-188-10000 psi), and a large part of the connecting pipe work are housed inside an air bath maintained at a uniform temperature to within about $\pm 0.1{ }^{\circ} \mathrm{C}$ of the required temperature. Air bath is an insulating box has the dimensions $(120 \mathrm{~cm} \times 50 \mathrm{~cm} \times 130 \mathrm{~cm})$.

The air bath temperature was controlled by a thyristor controller, and heat was provided by $1 \mathrm{KW}$ element. Heating and air circulation within the bath were accomplished using a combined heater-extractor fan unit was installed in the above of the one of the sides of the bath. The boundaries of the air bath are shown as a broken line as in Fig. (1).

Two Heise pressure gauges $(0-300$ bar) in increments of 0.5 bar were connected to the recycle line immediately above the equilibrium cell and the vapor sampling bomb, as shown in Fig. (1).

The piping in the high pressure part of the apparatus is of stainless steel, though copper piping is used for the compressed air line leading to the circulation pump, and plastic tubing is used to connect the manometer to the expansion system.

The pumping rate of the circulation pump was controlled by regulating the compressed air supply using a regulator valve.

The expansion system is that part of the apparatus which contains the contents of the vapor sampling bomb. The greater part of the volume of the system is that of the expansion vessel though the glass receiving vessels, which were used to collect the heavy component; and the connecting tubing contribute to it. The expansion vessel is a bottle and it is placed in a wooden box for insulating and has an approximate capacity of 34.5 liter and the exact volume of the expansion system was 35.01 liter.

The solid component was inserted into the lower part of the knit-mesh cylinder and was covered with a layer of knitmesh packing to prevent the solid particles from being carried over in the extracted stream. The knit-mesh cylinder containing the solid was inserted into the equilibrium cell and the cover was closed.

The apparatus was then evacuated to remove traces of air by using a rotary vacuum pump. The carbon dioxide may be forced in the system at point $b$. It is supplied from a cylinder and its pressure may be raised, if required, using the mercury injection pump (Ruska Type). The inlet valve is connected to the gas cylinder via a filter with a 15 micron mesh to prevent dust from the gas cylinder entering the apparatus. The valves $\mathrm{E}, \mathrm{F}$, and $\mathrm{C}$ were shut. Gas was then recirculated through the equilibrium cell and vapor sampling bomb for a period of at least 15 minutes. It was found that, if there was no leak in the equipment, the pressure registered by the gauge become steady by the end of the pumping period suggesting that equilibrium had been achieved (subsequent tests described verified that equilibrium was virtually complete after 10 minutes pumping [29]. The sampling bomb was then valve off and the composition of the vapor sample was determined.

The vapor sampling unit consists of an expansion vessel which is initially evacuated and the pressure in which is measured using a mercury manometer, and two glass collecting vessels. In order to determine the amounts of the extract and extractant present, the contents of the vapor sampling bomb are allowed to flow very gently into the expansion system via the collecting vessels. The number of moles (and hence the weight) of the light component is calculated from 


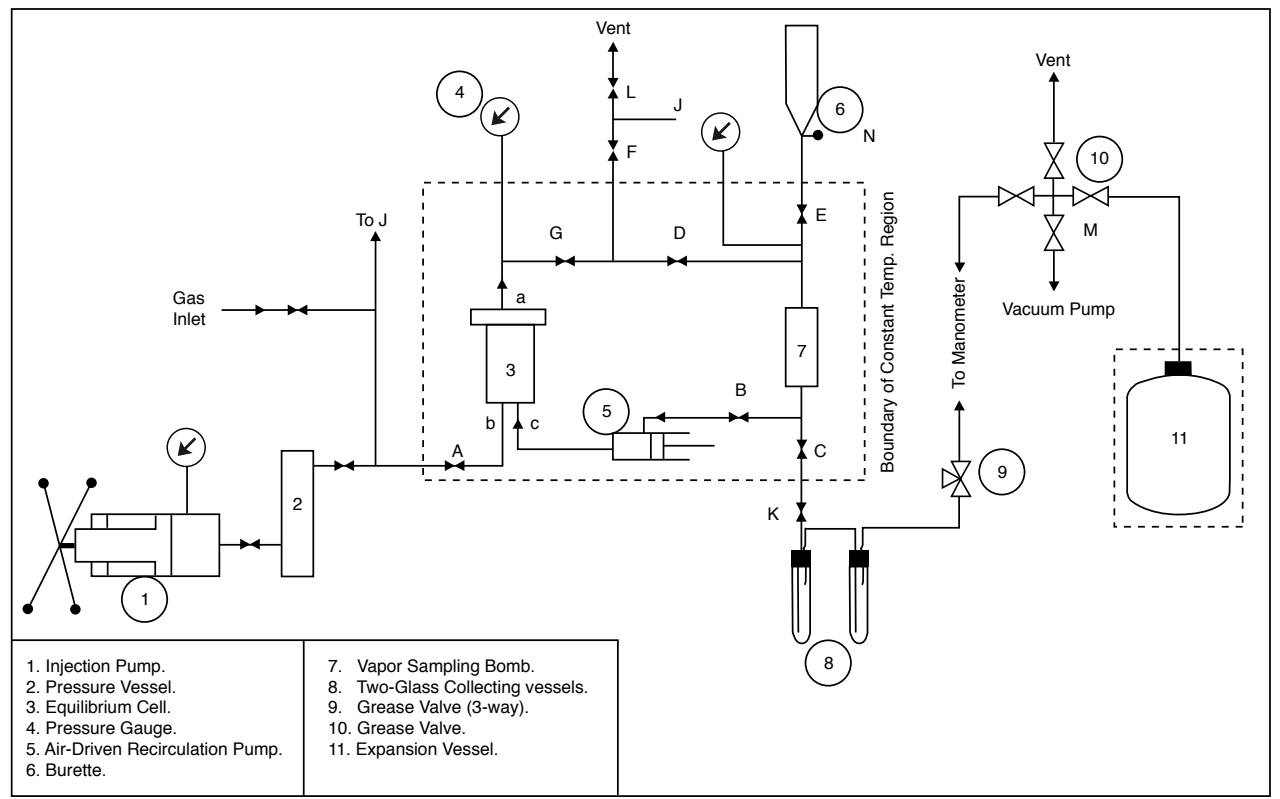

Fig. (1). Layout of equipment for equilibrium gas compositions measurements over solid phase.

the rise in pressure in the expansion system and the weight of extract is determined by transferring this to the glass collecting vessels and then weighing these. Some extract collects directly in these vessels during the expansion process. Much is however left behind in the vapor sampling bomb and lines leading from this to the collecting vessels. This is washed into the vessel using a suitable volatile liquid solvent, which is subsequently evaporated off.

\section{RESULTS AND DISCUSSION}

About $50 \mathrm{~g}$ of naphthalene was placed in a knit-mesh cylinder. This cylinder was placed in the equilibrium cell as shown in Fig. (2). The contents were contacted with recirculated compressed carbon dioxide at temperature 308.15 $\mathrm{K}$ and pressures up to 120 bar to insure that the apparatus would provide accurate and reliable equilibrium solubilities. The most important proof test was to compare the measured values of naphthalene solubility with those of McHugh \& Paulaitis [9]. Three equilibrium vapor samples were isolated in the vapor sampling bomb. The extract was washed into the glass collecting vessels shown in Fig. (1) with n-pentane solvent. The n-pentane was then evaporated off in a vacuum oven at temperature $303.15 \mathrm{~K}$ and pressure of 20 torr. The amount of extract in each sample was determined by weighing. The equilibrium solubilities (y) are compared with McHugh \& Paulaitis [9] data, the average deviation is only $4.14 \%$. The results are shown in Table (3).

The mole fraction solubilities of naphthalene and phenanthrene are measured at the temperature range of (308.15$323.15 \mathrm{~K})$ below the melting points of naphthalene (353.15 $\mathrm{K})$ and phenanthrene $(373.75 \mathrm{~K})$ to keep the naphthalene and phenanthrene in solid phase and the pressures up to $200 \mathrm{bar}$ as shown in Fig. (3) and Fig. (4) with those from literature. It may be seen that these results agree well with those obtained by McHugh \& Paulaitis [9], Richter \& Sovova [13], Unlu [16], Baskaya [17], King et al. [1], and Lim et al. [30] for the $\mathrm{CO}_{2}$-naphthalene system and Kurink et al. [10], Johnston et al. [11] and Dobbs et al. [31] for the $\mathrm{CO}_{2}$-phenanthrene system.
The $308.15 \mathrm{~K}$ isotherm is characteristic of solid solubility behavior at temperatures near the critical temperature of the supercritical carbon dioxide solvent. At this temperature, large changes in solubility occur for relatively small changes in pressure around the critical pressure of the carbon dioxide solvent; however, the maximum solubility at elevated pressures comparatively modest, in this case, the naphthalene mole fraction approaches 0.016 and for phenanthrene approaches 0.0014 . The $313.15 \mathrm{~K}, 318.15 \mathrm{~K}$ and $323.15 \mathrm{~K}$ isotherms are exhibit essentially the same behavior, the changes in solubility with pressure near the critical point of carbon dioxide are somewhat less dramatic, but the maximum solubility at elevated pressures is greater than that at $308.15 \mathrm{~K}$.

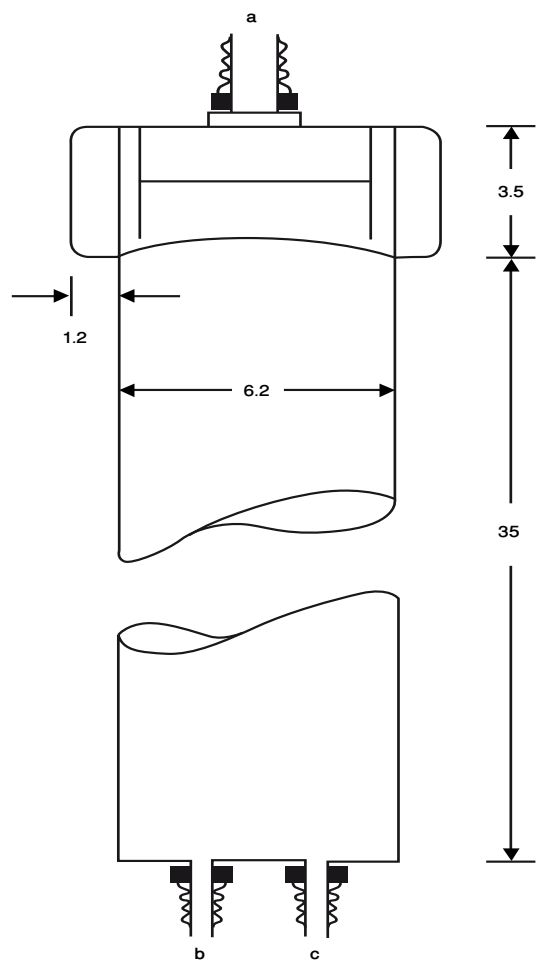

Fig. (2). High pressure cell (all dimensions in $\mathrm{cm}$ ). 
Table 3. Comparison of Test Data with Those of McHugh \& Paulaitis [9] for $\mathrm{CO}_{2}$-naphthalene System at Temperature $308.15 \mathrm{~K}$

\begin{tabular}{|c|c|c|c|}
\hline \multirow{2}{*}{\begin{tabular}{c} 
Pressure (bar) \\
\cline { 3 - 4 }
\end{tabular}} & Mass of naphthalene collected (gm) & Mole fraction of naphthalene $\left(\mathbf{y} x 0^{3}\right)$ \\
\cline { 3 - 4 } & & Present work & 8.13 \\
\hline \hline 90 & 0.5161 & 7.9220 & 9.95 \\
\hline 100 & 0.6822 & 9.8434 & 12.41 \\
\hline
\end{tabular}
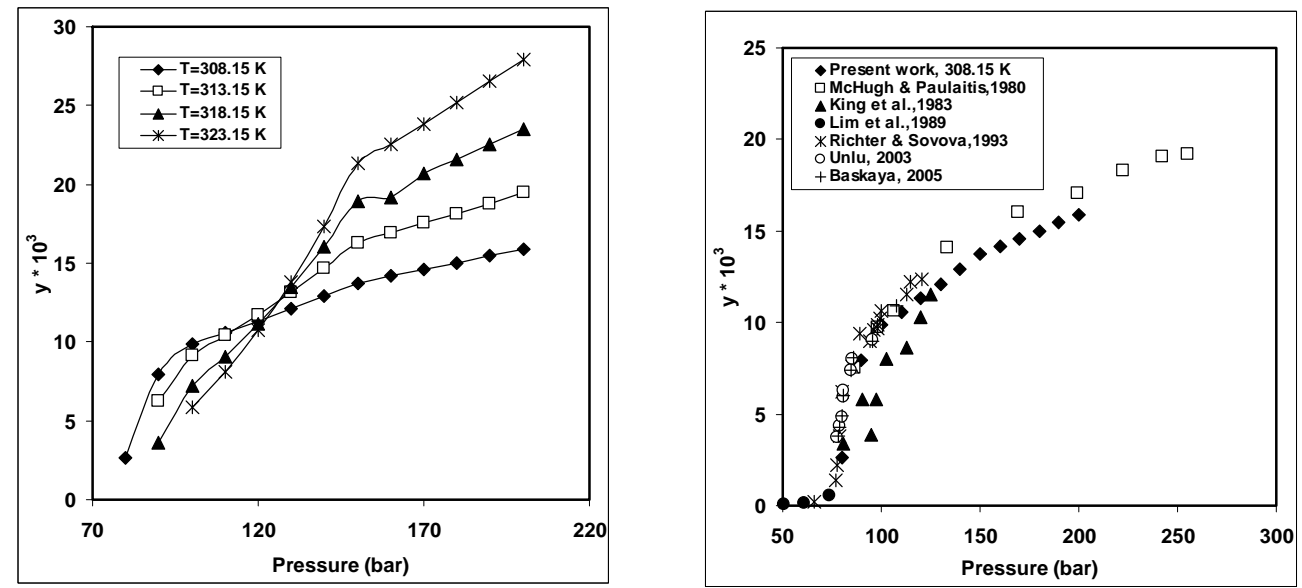

Fig. (3). The mole fraction solubility (y) of naphthalene in supercritical $\mathrm{CO}_{2}$ as a function of pressure at temperatures studied.
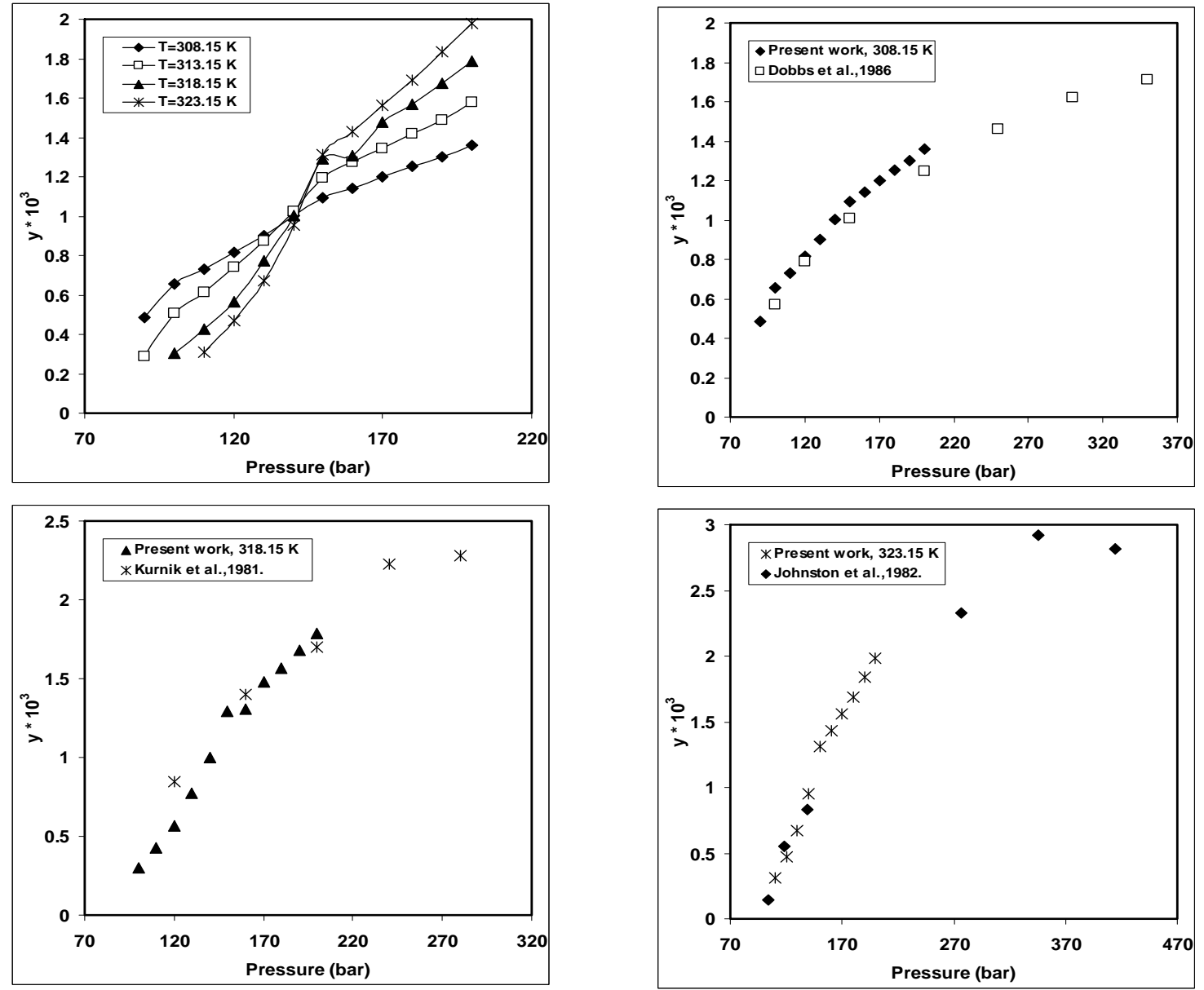

Fig. (4). The mole fraction solubility (y) of phenanthrene in supercritical $\mathrm{CO}_{2}$ as a function of pressure at temperatures studied. 
It is clear that the solubility of phenanthrene in supercritical carbon dioxide is less than that for naphthalene at the same conditions, because partially, the vapor pressure of naphthalene is higher than that of phenanthrene at a given temperature.

The effects of temperature and pressure on the solubility of naphthalene and phenanthrene in compressed carbon dioxide are shown in Fig. (5). The solubility versus temperature isobars has positive slopes in the high pressure region, and the negative slope in the low pressure regions. This is due to the two competing effects of temperature on the vapor pressure of the solute and the density of the fluid. The density is more sensitive to temperature near the critical pressure than at higher pressures. At these near-critical pressures, this density decrease with increasing temperatures dominates the effect on vapor pressure leading to negatively sloped isobars. At the higher pressure, the dominate temperature effect is on the vapor pressure giving positively sloped isobars.

When discussing the solubilities of solid components in compressed gases it is sometimes convenient to work in terms of the enhancement factor (E). This is the enhancement of the actual mole fraction solubility of the solid component $\left(\mathrm{y}_{\mathrm{i}}\right)$ over the "ideal" value $\left(P_{2}^{s u b} / P\right)$. The enhance-

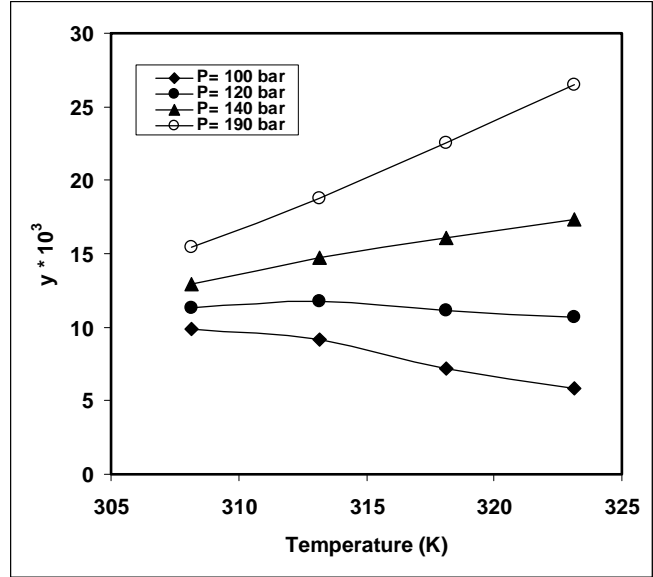

(a) Naphthalene ment factor for naphthalene and phenanthrene contacted with carbon dioxide as a function of the density of pure carbon dioxide under the given conditions shown graphically in Fig. (6). The relationship between $\log (\mathrm{E})$ and density is linear over the range studied.

It may be seen that the enhancement factor of phenanthrene is higher than that of naphthalene under the same conditions, because of the vapor pressure of naphthalene is higher than the vapor pressure of phenanthrene at a given temperature though the actual solubilities of phenanthrene are lower than those for naphthalene.

In general, the extraction of solid components depends strongly upon the density of the extracting fluid (carbon dioxide) and only becomes appreciable when the critical density is exceeded.

A major goal of the present work is to predict the experimental data by using physical properties of the pure components with adjustable parameter. Cubic equations of state along with the mixing rules given by equations (1) and (2) are used commonly for correlating experimental data of supercritical mixtures.

Figs. (7) and (8) show reasonable agreement between present work results and the data predicted by RK-EOS,

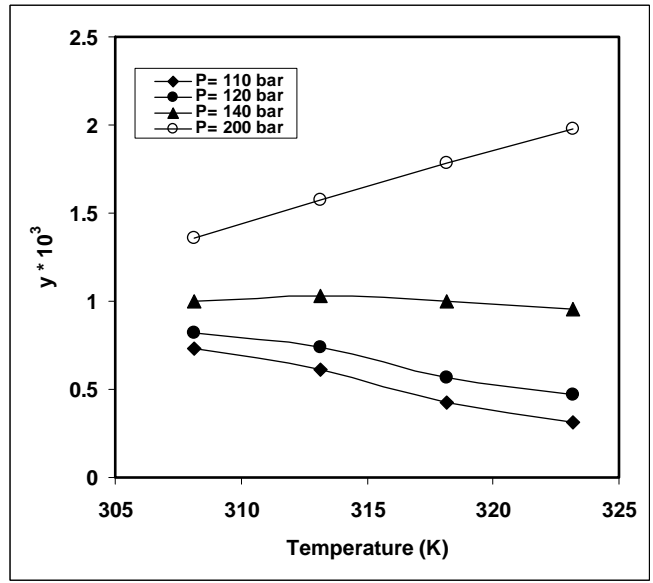

(b) Phenanthrene

Fig. (5). Mole fraction solubility (y) of naphthalene and phenanthrene in $\mathrm{CO}_{2}$ as a function of temperature at constant pressures.

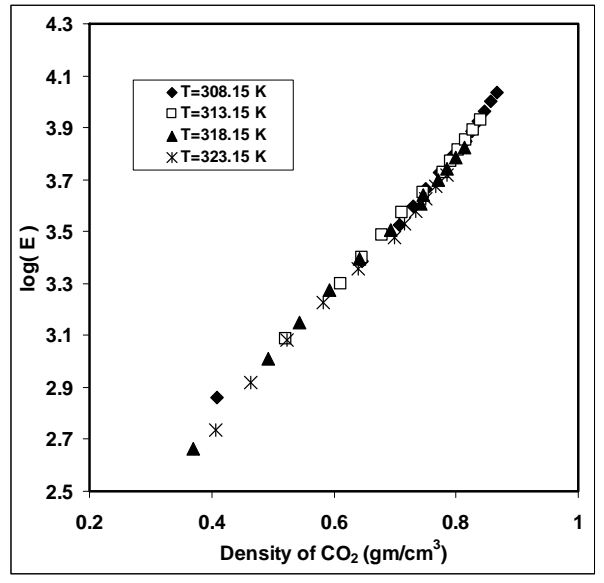

(a) Naphthalene

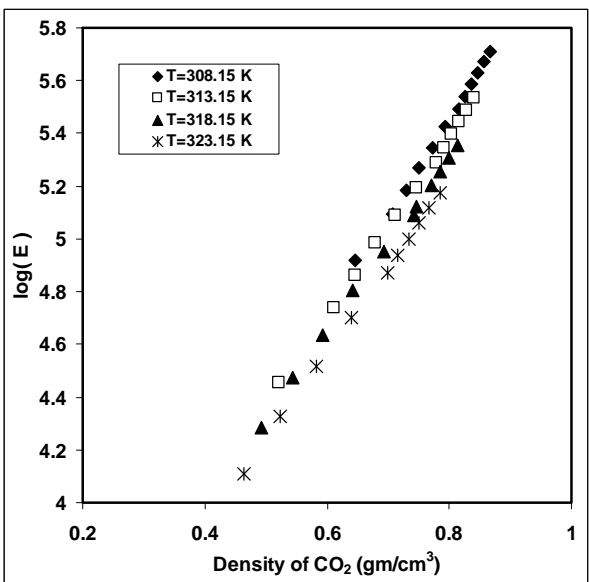

(b) Phenanthrene

Fig. (6). The enhancement factor (E) in compressed $\mathrm{CO}_{2}$ as a function of density of extractant. 


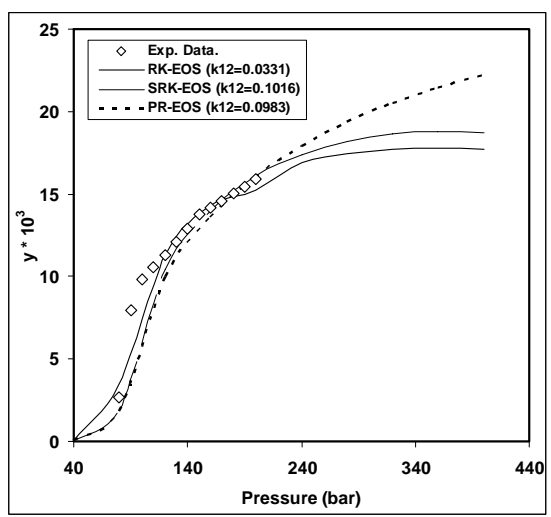

(a) $\mathrm{T}=308.15 \mathrm{~K}$

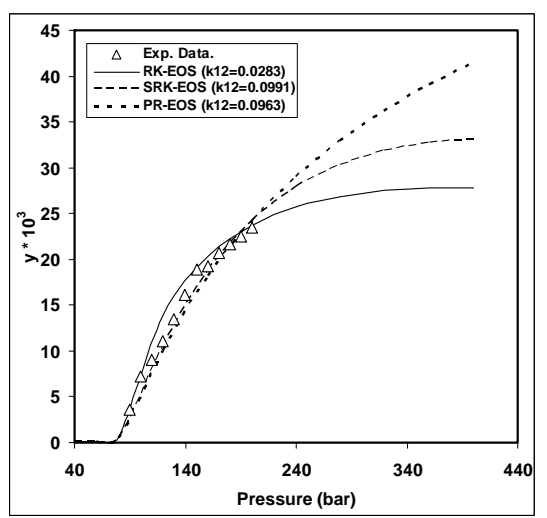

(c) $\mathrm{T}=318.15 \mathrm{~K}$

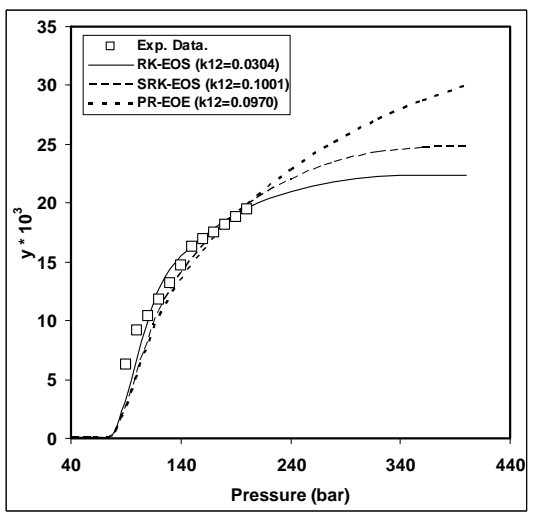

(b) $\mathrm{T}=313.15 \mathrm{~K}$

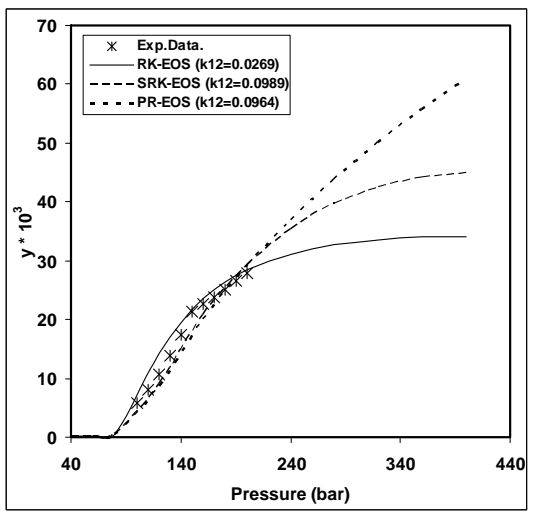

(d) $\mathrm{T}=323.15 \mathrm{~K}$

Fig. (7). The solubility of naphthalene in $\mathrm{CO}_{2}$ curve predicted by the RK-EOS, SRK-EOS and PR- EOS at temperatures studied.

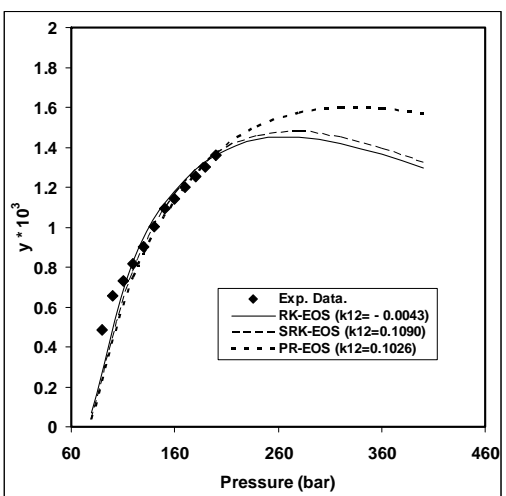

(a) $\mathrm{T}=308.15 \mathrm{~K}$

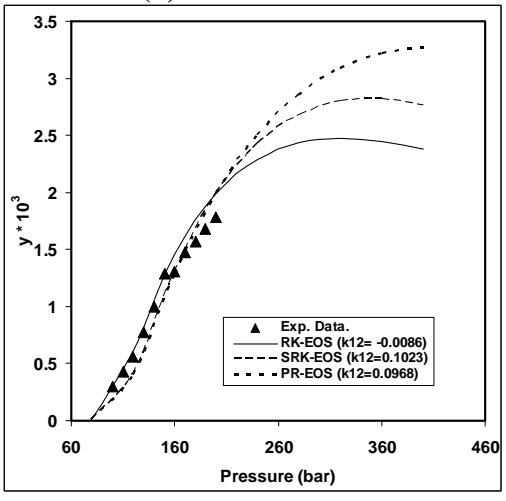

(c) $\mathrm{T}=318.15 \mathrm{~K}$

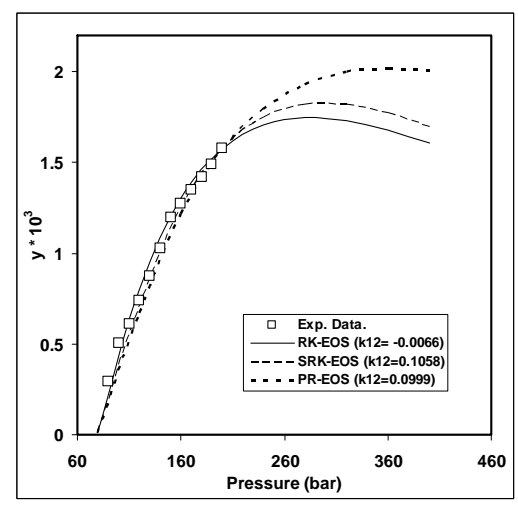

(b) $\mathrm{T}=313.15 \mathrm{~K}$

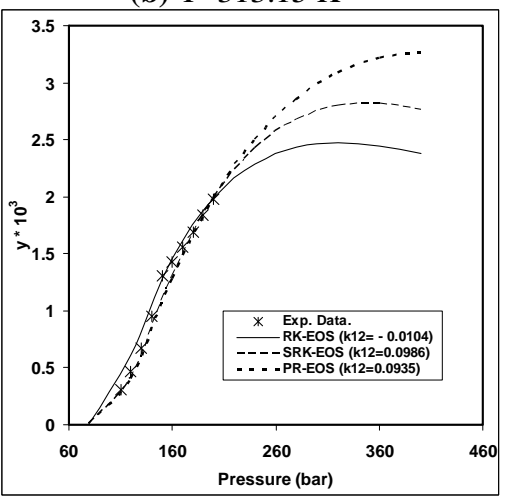

(d) $\mathrm{T}=323.15 \mathrm{~K}$

Fig. (8). The solubility of phenanthrene in $\mathrm{CO}_{2}$ curve predicted by the RK-EOS, SRK-EOS and PR-EOS at temperatures studied. 
SRK-EOS and PR-EOS. Interaction parameters $\mathrm{k}_{12}$ 's given in Tables (4) and (5) were used for these three equations of state. It may be seen that the interaction parameter $\left(\mathrm{k}_{12}\right)$ for each equation is decreased relatively with increasing the temperature, because of the solubilities are governed primarily by vapor pressure, which depends on the temperature and only secondarily by carbon dioxide-solid component interactions in the SCF phase.

The value of $\left(\mathrm{k}_{12}\right)$ for each temperature is determined by a series of values of $\left(\mathrm{k}_{12}\right)$ assumed, and the solubilities are calculated for each isotherm pressure. The accepted value of $\left(\mathrm{k}_{12}\right)$ is the one which yields the minimum sum of average absolute relative deviation (AARD) that is,

$\% A A R D=\frac{100}{N} \sum_{i=1}^{N}\left|\frac{(y)_{\text {cal. }}-(y)_{\text {exp. }}}{(y)_{\text {exp. }}}\right|$

where $\mathrm{N}$ is the number of data points. Tables (4) and (5) show the \% AARD for the equations of state used and it can be seen that the RK-EOS gives \% AARD less than the other two equations of state.

\section{CONCLUSIONS}

1. As expected, the extraction of low volatility solid components depends strongly upon the density of the extracting fluid (carbon dioxide) and only becomes appreciable when the critical density is exceeded.

2. The $308.15 \mathrm{~K}$ isotherm for the carbon dioxide-solid system is characteristic of solid solubility behavior at temperatures near the critical temperature of the carbon dioxide solvent, because large changes in solubility occur for relatively small changes in pressure around the critical pressure of the carbon dioxide at this temperature, as it was verified by other researchers $[9,10]$.
3. There are many options available in supercritical fluid extraction for achieving and controlling the desired selectivity, which is extremely sensitive to variations in pressure, temperature.

4. It is possible to collate vapor phase data for the carbon dioxide-solid system adequately by using the cubic equations of state.

5. The applicability of supercritical extraction is highly dependent on our ability to model and predict phase equilibrium in complex systems. Supercritical fluid systems are especially challenging because of the high compressibility and the asymmetry of the systems encountered.

6. Supercritical fluid extraction is often inappropriate for separations because easier methods are available, but when it is needed it is a very powerful tool.

\section{ABBREVIATIONS}

$\begin{array}{lll}\mathrm{AARD} & = & \text { Absolute average relative deviation } \\ \mathrm{EOS} & = & \text { Equation of state } \\ \mathrm{PR} & = & \text { Peng-Robinson } \\ \mathrm{RK} & = & \text { Sedlich- Kwong } \\ \mathrm{SCF} & = & \text { Soave }- \text { Redlich- Kwong } \\ \mathrm{SRK} & = & \begin{array}{l}\text { Parameters in equation of state of pure } \\ \text { NOTATIONS }\end{array} \\ \mathrm{a}_{\mathrm{i}}, \mathrm{b}_{\mathrm{i}} & = & \text { Pamponent } \\ \mathrm{a}_{\mathrm{m}}, \mathrm{b}_{\mathrm{m}} & & \text { ture } \\ f_{i}^{S C F} & = & \text { Partial molal fugacity in gas phase, bar }\end{array}$

Table 4. The Interaction Parameters $\left(\mathrm{k}_{12}\right.$ 's) and Average Absolute Relative Deviations (AARD) for each Equation of State of CO $\mathbf{O}_{2}$ Naphthalene System

\begin{tabular}{|c|c|c|c|c|c|c|}
\hline \multirow{2}{*}{$\mathbf{T}(\mathbf{K})$} & \multicolumn{2}{|c|}{ RK-EOS } & \multicolumn{2}{|c|}{ SRK-EOS } & \multicolumn{2}{|c|}{ PR-EOS } \\
\hline & $k_{12}$ & $\%$ AARD & $k_{12}$ & $\%$ AARD & $k_{12}$ & $\%$ AARD \\
\hline 308.15 & 0.0331 & 3.10 & 0.1016 & 5.75 & 0.0983 & 7.68 \\
\hline 313.15 & 0.0304 & 2.72 & 0.1001 & 6.82 & 0.0970 & 8.56 \\
\hline 318.15 & 0.0283 & 6.73 & 0.0991 & 9.98 & 0.0963 & 11.25 \\
\hline 323.15 & 0.0269 & 6.45 & 0.0989 & 10.08 & 0.0964 & 11.28 \\
\hline
\end{tabular}

Table 5. The Interaction Parameters $\left(\mathrm{k}_{12}\right.$ 's) and Average Absolute Relative Deviations (AARD) for each Equation of State of CO ${ }_{2}$ Phenanthrene System

\begin{tabular}{|c|c|c|c|c|c|c|}
\hline \multirow{2}{*}{$\mathbf{T}(\mathbf{K})$} & \multicolumn{2}{|c|}{ RK-EOS } & \multicolumn{2}{|c|}{ SRK-EOS } & \multicolumn{2}{|c|}{ PR-EOS } \\
\hline & $k_{12}$ & $\%$ AARD & $k_{12}$ & $\%$ AARD & $k_{12}$ & $\%$ AARD \\
\hline 308.15 & -0.0043 & 5.76 & 0.1090 & 7.03 & 0.1026 & 8.67 \\
\hline 313.15 & -0.0066 & 7.68 & 0.1058 & 10.94 & 0.0999 & 12.81 \\
\hline 318.15 & -0.0086 & 9.31 & 0.1023 & 7.52 & 0.0968 & 9.19 \\
\hline 323.15 & -0.0104 & 11.31 & 0.0986 & 12.88 & 0.0935 & 14.12 \\
\hline
\end{tabular}




\begin{tabular}{|c|c|c|}
\hline$f_{i}^{S}$ & $=$ & $\begin{array}{l}\text { Partial molal fugacity in solid phase, } \\
\text { bar }\end{array}$ \\
\hline $\mathrm{k}_{\mathrm{ij}}$ & $=$ & $\begin{array}{l}\text { Interaction parameter in mixing rules, } \\
\text { eq. (3) }\end{array}$ \\
\hline $\mathrm{n}$ & $=$ & Number of components, eq.s (1) and (2) \\
\hline $\mathrm{n}$ & $=$ & Total number of mole, eq. (6) \\
\hline $\mathrm{n}_{\mathrm{i}}$ & $=$ & Number of moles of component $i$, mole \\
\hline $\mathrm{N}$ & $=$ & Number of data points \\
\hline $\mathrm{P}$ & $=$ & Total system pressure, bar \\
\hline$P_{c}$ & $=$ & Critical pressure, bar \\
\hline$P^{\text {sub }}$ & $=$ & Sublimation pressure, bar \\
\hline $\mathrm{R}$ & $=$ & $\begin{array}{l}\text { Universal gas constant ( } 0.08314 \text { bar lit./ } \\
\text { mol K) }\end{array}$ \\
\hline $\mathrm{T}$ & $=$ & Absolute temperature, $\mathrm{K}$ \\
\hline $\mathrm{T}_{\mathrm{C}}$ & $=$ & Absolute critical temperature, $\mathrm{K}$ \\
\hline$v_{i}^{S}$ & $=$ & Molar volume of pure solid, (lit. / mol) \\
\hline$\underline{\mathrm{V}}$ & $=$ & Total system volume, (lit.) \\
\hline$v^{\mathrm{v}}$ & $=$ & Molar volume of vapor phase, (lit./mol) \\
\hline $\mathrm{y}_{\text {calc }}$ & $=$ & $\begin{array}{l}\text { Calculated or predicted mole fraction } \\
\text { solubility }\end{array}$ \\
\hline$y_{\exp }$ & $=$ & Experimental mole fraction solubility \\
\hline & $=$ & Mole fraction solubility of component $i$ \\
\hline & $=$ & Compressibility factor \\
\hline
\end{tabular}

Greek letters

$\begin{array}{lll}\alpha & = & \text { Constant in eq. (10) } \\ \beta & = & \text { Constant in eq. (10) } \\ \omega & = & \text { Acentric factor } \\ \phi_{i} & & \begin{array}{l}\text { Partial molal fugacity coefficient of } \\ \text { component } \mathrm{i}\end{array} \\ \phi_{i}^{S C F} & = & \begin{array}{l}\text { Partial molal fugacity coefficient of } \\ \text { component i in gas phase, eq. (8) }\end{array}\end{array}$

\section{Superscripts}

$\begin{array}{lll}\mathrm{SCF} & = & \text { Supercritical fluid } \\ \mathrm{S} & = & \text { Solid } \\ \mathrm{Sub} & = & \text { Sublimation }\end{array}$

\section{Subscripts}

$\begin{array}{lll}\mathrm{c} & = & \text { Critical property } \\ \mathrm{m} & = & \text { Mixture } \\ \mathrm{ij} & = & \text { Component indices } \\ \exp & = & \text { Experimental measurement } \\ \text { calc } & = & \text { Predicted value }\end{array}$

\section{REFERENCES}

[1] M. B. King, F. H. Alderson, D. M. Kassim, K. M. Kassim, J. R. Sheldon, and R. S. Mahmud, "Some Vapor/Liquid and Vapor/Solid Equilibrium Measurements of Relevance for Supercritical Extraction Operations, and Their Correlation" presented as a Chapter in the text "Chemical Engineering at Supercritical Fluid Conditions",
M. E. Paulaitis, J. M. L. Penninger, R. Gray, and P. Davidson (Eds.), Ann. Arbor. Sci., Chap.2, pp.31-80, 1983.

[2] B. Francesca, D. V. Sara, and G. Fausto, "Supercritical extraction column for separation of limonene and citral; Paper no. 782, University of Roma, Italy, 2000.

[3] M. N. Ponte, The thermodynamics of supercritical fluids, Science and Technology Faculty, Nova de Lisbon University, Portugal, pp.40-42, 2001.

[4] J. R. Dean, "Appications of Supercritical Fluids in Industrial Analysis", Boca Raton: Chapman \& Hall, 1993.

[5] A. M. A. Karim, D. M. Kassim, and M. A. Zablouk, "Phase equilibrium study for the separation of solid component using supercritical carbon dioxide entrained with liquid solvent", Al-Muhandis Journal, The Iraqi Society of Engineers, Iraq, Serial-146 - No.2, pp. $52-73$, June 2001

[6] G. B. Solórzano, "Supercritical fluid technology: computational and experimental equilibrium studies and design of supercritical extraction processes", Ph.D. Thesis, Graduate School, University of Notre Dame, USA, 2004.

[7] M. McHugh, and V. Krukonis, "Supercritical fluid extraction, principles and practice" Butterworth, 1986.

[8] A.W. Francis, "Ternary systems of liquid carbon dioxide", J. Phys. Chem., Vol. 58, pp.1099, 1954.

[9] M. McHugh and M. E. Paulaitis, " Solid solubilities of naphthalene and biphenyl in supercritical carbon dioxide", J. Chem. Eng. Data, Vol. 25, pp. 326-329, 1980.

[10] R. T. Kurnik, S. J. Holla, and R. C. Reid, "Solubility of solids in supercritical carbon dioxide and ethylene", J. Chem. Eng. Data, Vol. 26, pp. 47-51, 1981.

[11] K. P. Johnston, D. H. Ziger, and C. A. Eckert, "Solubilities of hydrocarbon solids in supercritical fluids. The Augmented van der Waals treatment", Ind. Eng. Chem. Fundam., Vol. 21, pp. 191-197, 1982

[12] K. P. Johnston and C. A. Eckert, "An analytical Carnahan - Starling - van der Waals model for solubility of hydrocarbon solids in supercritical fluids", AIChE J., Vol. 27, No.5, pp. 773, 1981.

[13] M. Richter and H. Sovova', "The solubility of two monoterpenes in supercritical carbon dioxide", Fluid Phase Equilibria, Vol. 85, pp. 285-300, 1993

[14] M. Sauceau, J. Fages, J. -J. Letourneau, and D. Richon, "Solid solubilities in supercritical phases: New apparatus, measurements and modeling" fifth International Symposium on Supercritical Fluids, Atlanta, Ga., April 2000.

[15] R. Hartono, G. A. Mansoori, and A. Suwono, "Prediction of solubility of biomolecules in supercritical solvents", Chem. Eng. Sci., Vol. 56, pp. 6949-6958, 2001

[16] O. Unlu, "Phase equilibrium at supercritical (SC) conditions: Phase equilibrium analysis of guaifenisin in supercritical $\mathrm{CO}_{2}$ and cosolvent mixtures, Chemical Engineering", M.Sc. Thesis, The University of Akron, Akron, pp. 126, 2003.

[17] F. S. Baskaya, "Phase equilibrium at supercritical (SC) conditions: Solubility analysis of curcumin in supercritical carbon dioxide and co-solvent mixtures, and phase equilibrium analysis of Cis-1,4(Poly)Isoprene in propane and co-solvent mixtures", M.Sc. Thesis, The University of Akron, Akron. p. 52, 2005.

[18] A. M. A. Karim and S. I. Abdul Khader, "Phase equiliberia modeling for separation of solid mixtures by supercritical carbon dioxide on Excel" Diyala J. For Applied Researches, Vol. 4, No.1, Diyala University, Diyala, Iraq, pp. 119-150, 2008.

[19] A. Ajchariyapagorn, P. L. Douglas, and S. Douglas, "Prediction of solubility of solid biomolecules in supercritical solvents using group contribution methods and equations of state", Am. J. Food Technol., Vol. 3, No. 3, pp. 275-293, 2008.

[20] M. S. Shin and H. Kim, " Solubility of triclosan in supercritical carbon dioxide and its application to micronization process", Clean Technol., Vol. 14, No. 3, pp. 153-159, 2008

[21] A. M. A. Karim, "Influence of property estimation techniques on thermodynamic modeling of solubility of C. I. disperse orange 30 dye in supercritical $\mathrm{CO}_{2}$ " in Sixth Engineering Conference, College of Engineering, University of Baghdad, Baghdad, Iraq, 5-7 April, Vol. 6, pp. 41-54, 2009.

[22] A. M. A. Karim, A. K. Mutlag, "Artificial neural networks modeling of phase equilibrium for the separation of phenanthrene using supercritical $\mathrm{CO}_{2} "$ First Information Technology Conference / Computer Engineering and Information Technology Dept. / University of Technology / Baghdad - Iraq / 21-23 April, 2009. 
[23] G. Xu, A. M. Scurto, M. Castier, J. F. Brennecke and M. A. Stadtherr, "Reliable computation of high-pressure solid- fluid equilibrium", Ind. Eng. Chem. Res., Vol. 39: pp.1624-1636, 2000.

[24] M. A. McHugh, and T. J. Yogan, J. Chem. Eng. Data, No.29: pp.112, 1984, Cited in reference 25 .

[25] S. Ravipaty, and D. J. Chesney, "Study on critical points of carbon dioxide + single and multicomponent solid solute systems", Department of Chemistry, Michigan Technological University, Houghton, USA, 2003. http://www.supercriticalfluids.com/ publications Resource website: http://sunny.vemt.bme.hu/sfe/angol/ supercritical.html

[26] J. Prausnitz, "Molecular thermodynamics of fluid-phase equilibria", 3rd Edition, 1998. Resource website: www.technicalbookstore.com.

[27] C. Lazo, "Measuring and modeling of mixed adsorption isotherms for supercritical fluid chromatography", M. Sc. Thesis; Technology University of Hamburg, Germany, 2000.
[28] A. M. A. Karim, "Phase equilibrium study for the separation of solid and liquid components using supercritical carbon dioxide", Ph.D. Thesis, Chem. Eng. Dept., Technology University, Baghdad, Iraq, 1998.

[29] D. M. Kassim, D. Al-Sammerrai, and F. Paulus, "Near critical carbon dioxide extraction of oxidation products from base stock mineral oils", Sep. Sci. Tech., Vol.22, pp: 157-164, 1987.

[30] G. -B. Lim, G. D. Holder, and Y. T. Shah, "Solid-fluid mass transfer in a packed bed under supercritical conditions", in Supercritical Fluid Science and Technology, K. P. Johnston and J. M. L. Penninger, Eds., ACS, No.406, Chap.24, 1989.

[31] J. M. Dobbs, J. M. Wong, and K. P. Johnston, "Nonpolar cosolvents for solubility enhancement in supercritical fluid carbon dioxide", J. Chem. Eng. Data, Vol.31, pp.303-308, 1986.

(C) Karim et al.; Licensee Bentham Open.

This is an open access article licensed under the terms of the Creative Commons Attribution Non-Commercial License (http://creativecommons.org/licenses/ by-nc/3.0/) which permits unrestricted, non-commercial use, distribution and reproduction in any medium, provided the work is properly cited. 